\title{
Prevention of drug abuse and misuse
}

\begin{abstract}
Individuals begin the drug addiction problems by misuse of prescription drugs. Confusion exists because the correct use of prescribed medications for pain, anxiety, and even hypertension commonly produces tolerance and physical dependence. Sometimes patient depend upon the medication by habit or by error. When overdose or misuse of the drug takes for long times by an individual, the drug cause serious side effects on the body which include nausea, vomiting, CNS disturbance, blurring of vision, irritation, mood upset and tendency to go somewhere. These side effects are possible due to habitual acceptance of the required dose which possibly produce side effect. Treatments are available for these habitual drugs but they need some times to effect on the human body.
\end{abstract}

Keywords: cocaine, physical dependence, adverse effects
Volume 4 Issue 4 - 2018

\section{Firoz Khan}

Department of Pharmaceutical Technology, Meerut Institute of Engineering and Technology, India

Correspondence: Mr Firoz khan; Department of Pharmaceutical Technology, Meerut Institute of Engineering and Technology, Meerut, N.H-58, Delhi-Roorkee Highway, Baghpat Bypass Road Crossing Meerut, India, Email fkpharmacy@gmail.com

Received: August 0I, 20I8 | Published: August 22, 2018

\section{Introduction}

The presence of psychotic symptoms is widespread in psychiatric disorders. Delusions and hallucinations, which are among the main symptoms of psychosis, belong to the schizophrenic spectrum. In the bipolar disorder, manic or depressive episodes, as well as mixed states, are frequently marked by psychotic symptoms. Moreover, psychosis may set in after substance abuse, often intervening with the effect of making the clinical picture indistinguishable from that of a primary psychosis. Psychosis induced by substances of abuse is most commonly developed by cannabinoids, stimulants, hallucinogens, alcohol and polyabuse. $1)$.

Classification of drugs that are used for misuse and abuse (Table

Table I Table showing drugs used in abuse and misuse

\begin{tabular}{llll}
\hline $\begin{array}{l}\text { Sr. } \\
\text { No. }\end{array}$ & $\begin{array}{l}\text { Types of } \\
\text { drugs }\end{array}$ & Examples & Effects \\
\hline I. & $\begin{array}{l}\text { Sedatives and } \\
\text { Tranquilizers }\end{array}$ & $\begin{array}{l}\text { Barbiturates, } \\
\text { Benzodiazepines }\end{array}$ & $\begin{array}{l}\text { Depress CNS activity, } \\
\text { give feeling of calmness, } \\
\text { relaxation, drowsiness }\end{array}$ \\
2. & $\begin{array}{l}\text { Opiate } \\
\text { narcotics }\end{array}$ & $\begin{array}{l}\text { Opium, Morphine, } \\
\text { Heroin, Codeine. }\end{array}$ & $\begin{array}{l}\text { Suppress brain activity, } \\
\text { relaxed pain. }\end{array}$ \\
3. & Stimulants & $\begin{array}{l}\text { Amphetamine, } \\
\text { Caffeine, Cocaine, }\end{array}$ & $\begin{array}{l}\text { Make a person more } \\
\text { wakeful, alert and active, } \\
\text { cause excitement. }\end{array}$ \\
& LSQ, Mescaline, & Alter thoughts, Feeling \\
asilocybin, Ganja, & and perceptions.
\end{tabular}

\section{CNS Depressants: Benzodiazepine Abuse}

Patients which are on the treatment of antipsychotic drug such as benzodiazepines, have a greater tendency to develop drug abuse. There are some patients who see benzodiazepines to create a "high". Benzodiazepines that have a quick beginning (Diazepam and Alprazolam) have a tendency to be most attractive among abusers. Example;

A. Typical dose: 5-20mg/day, Abuse dose: $1000 \mathrm{mg} /$ day. Abusers with Benzodiazepines treatment have a tendency to use other medication to enhance the duration \& effect.
B. Taking Diazepam 30min after oral dose of Methadone results in augmented "high" not obtainable with either drug alone., ${ }^{2,3}$

\section{Withdrawal symptoms: moderate dose usage}

I. Anxiety/Agitation, disturbed sleep, Dizziness, Muscle cramps.

II. High dose produce- Seizures and state of Delirium

\section{Control methods}

a. High dose abusers (deliberated) need detoxification in IPD.

b. Outpatient Rehabilitation Program is required after detoxification to prevent relapse.

c. Barbiturates abuse problems resemble those seen with Benzodiazepine in many ways. Treatment of abuse and addiction should be handled with similar to Benzodiazepine.

d. Medications require detoxification by gradual Dose Reduction.

\section{Opioids: Heroin abuse}

Psychosis (a severe mental disorder in which thought and emotions are so impaired that contact is lost with external reality) leading to Hallucinations. The condition of sensation such as feeling of warm, change in taste or a condition of high and pleasure can be produce by injecting a solution of Heroin. Opioids (Heroin and others) are frequently used in the form of other drugs with combination. Example of such combination as Heroin \& Cocaine (speedball).Cocaine reduces the sign of opiate withdrawal and Heroin reduces the irritability in chronic cocaine users. ${ }^{4}$

\section{Withdrawal syndrome}

Craving for opioids, Restlessness, Irritability, Nausea, vomiting, diarrhea, Muscle aches

Control Methods: It can be controlled by 3 different approaches;

A. The first and most commonly used approach depends on crosstolerance consists of transfer to a prescription opioid medication and then gradual doss reduction.

B. Secondly, detoxification with oral use of Clonidine. The dose should be start with $0.2 \mathrm{mg}$ in the beginning and must be treated according to the stage of the condition of disease and withdrawal severity. 
C. Thirdly, opioids withdrawal can be treated with medication by endogenous opioid system activation. i.e.

i. Acupuncture

ii. Transcutaneous Electrical Stimulation (TES)

iii. By using Methadone

iv. By preparation of Naltrexone.

\section{CNS stimulant: Cocaine}

Chewing of Coca leaves has possess gradual onset stimulant effect in the body and this practice of chewing the leaves produce a long abuse in today and for thousands of years. A solution of Cocaine Hydrochloride could be administered IV. Cocaine produces a dose dependent increase in heart rate and blood pressure accompanied by increased arousal, improved performance on tasks of vigilance and alertness and a sense of self-confidence and well being. Higher doses produce euphoria, which has a brief duration and often is followed by a desire for more drugs. Illegally cocaine can be found at low price. Cocaine is also available as alkaloidal cocaine (free base) which vaporizes when touch with heating. ${ }^{5}$ The availability of cocaine can be found with combination of other medication used for abuse. i.e.

A. Cocaine-Heroin(combination with opioid)

B. "Cocaine-Alcohol:"it reduce the irritability experienced during heavy cocaine used.

\section{Withdrawal symptoms}

Dysphoria, heavy dose produce depression, loss of sleep, fatigue, cocaine craving, bradycardia.

\section{Treatment}

A. Rehabilitation programs involving individual and group psychotherapy results in significant improvement in the majority of cocaine users. Various drugs has been tried in the form of placebo control trials. Topiramate reduces the relapse rate in alcoholic dependent on cocaine and alcohol.

B. Baclofen are used to reduce the condition of euphoria by cocaine and also withdrawal symptoms.

\section{Amphetamine}

Amphetamine and other drugs such as methamphetamine, phenmetrazine and dextroamphetamine has produce similar effect as cocaine. IV or smoked methamphetamine produces an abuse/ dependence syndrome similar to those of cocaine. Methamphetamine can be produced with ephedrine, a widely available non-prescription stimulant. ${ }^{6}$ Withdrawal symptoms \& Treatment (are similar as cocaine).

\section{Hallucinogens: Cannabinoids}

The cannabis plant has been used for production of Hemp fiber and from its presumed medicinal and psychoactive properties for centuries. The burning cannabis produce smoke; contain many chemicals such as tetrahydrocannabinol (THC) produces most of the characteristics effects of smoked Marijuana. The effect of marijuana produces change in mood, enhancement of perception and motivation, but the effect can be seen in terms of "high". The typical marijuana smokers experience a high that last about two hrs. During this time, there is impairment of cognitive function, perception, reaction time, learning and memory. ${ }^{7}$

\section{Withdrawal syndrome}

a) Irritability to others, Agitation, produce restlessness, asleep, Nausea, drowsiness cramping,

b) Compulsive or general cannabis abuser does not seem, by all accounts, to be inspired by the dread of withdrawal symptoms.

\section{Treatment}

There are no specific treatments with marijuana smokers. Some of the depressed patients can be treated with antidepressant drugs which are effective on the severity of the symptoms seen. Rimonabant is a CB-1 receptor blocker/antagonist used to reduce the acute effects of smoked marijuana.

\section{Stimulant \& Depressant:Alcohol}

Ethanol is also come in this class because it produced sedation and sleep. However, the initial effects of alcohol, particularly at low doses, often are perceived as stimulation.

A. Mild intoxication by alcohol is familiar to almost everyone, but the symptoms vary among individuals. Some experience motor incoordination and sleepiness.

B. Heavy consumers of alcohol not only acquire tolerance but also develop a state of physical dependence.

C. There is a cross tolerance with the use of other sedatives such as benzodiazepine (Diazepam, Alprazolam). ${ }^{8}$

\section{Withdrawal syndrome}

Tremor, Physical and mental Irritability, Nausea, Vomiting, High BP, Perceptual distortion, Confusion in the way of thinking, Seizures may be 6-48 hrs after taking last drink, Visual hallucinations comes under 12-48 hrs after last drink, a state of Delirium tremens comes under 48-96hrs after last drink.

\section{Treatments}

I. Detoxification needed in lethal condition.

II. Benzodiazepine (Oxazepam) is preferable at a dose of 15-30mg every 4-6hrs according to stage and severity of withdrawal.

III. Carbamazepine is an anticonvulsant; used to treat the withdrawal symptoms of alcohol but is less effective as benzodiazepines.

IV. Disulfiram produce unpleasant flushing when alcohol is ingested.

V. Reinforcing properties can be blocked by Naltrexone which result in decrease in the tendency of relapse in drinking of alcohol. ${ }^{9}$

\section{Discussion}

The relationship between substance abuse, misuse and psychosis is proven in this review. So, we can definitely say that the misuse of the drugs used in the treatment of neurological and other disorder have tendency to produce side effects which may be severe to the health. Taking long times drugs may also develops adverse drug side effects. So all be careful to avoid the physical dependence of the prescribed drugs. Before taking any drug have consult to the doctor to avoid drug abuse and misuse. 


\section{Conclusion}

Control of drug abuse and misuse generally includes Reduction (each day of $20 \%$ of daily dose), Substitution and Control (alcohol). They need some time but are effective in controlling the symptoms of life threatening disorders as well as maintaining the healthy living life.

\section{Acknowledgements}

None.

\section{Conflict of interest}

The author declares that there is no conflict of interest.

\section{References}

1. Maremmani AGI, Rovai L, Rugani $\mathrm{F}$ et al. Substance abuse and psychosis. The strange case of opioids. Eur Rev Med Pharmacol Sci. 2014;18(3):287-302.

2. VonLimbeekJ, Wouters L, Kaplan CD, etal. Prevalence of psychopathology in drug-addicted Dutch. $J$ Subst Abuse Treat. 1992;9(1):43-52.
3. Kuepper R, Van OSJ, Lieb R, et al. Continued cannabis use and risk of incidence and persistence of psychotic symptoms: 10 year follow-up cohort study. Br Med J. 2011;18(7):123-128.

4. Loga S, Loga zec S, Spremo M. Cannabis and psychiatric disorders. Psychiatr Danub. 2010;22:296-297.

5. Gonzalez-pinto A, Vega P, Ibanez B, et al. Impact of cannabis and other drugs on age at onset of psychosis. J Clin Psychiatry. 2008;69(8):1210 1216.

6. Maremmani I, Lazzeri A, Lovrecic $M$, et al. Diagnostic and symptomatological features in chronic psychotic patients according to cannabis use status. J Psychoactive Drugs. 2004;36(2):235-241.

7. Dragt S, Nieman DH, Becker HE, et al. Age of onset of cannabis use is associated with age of onset of high-risk symptoms for psychosis. Can J Psychiatry. 2010;55(3):165-171.

8. Srisurapanont M, Arunpongpaisal S, Wada K, et al. Comparisons of methamphetamine psychotic and schizophrenic symptoms: A differential item functioning analysis. Prog Neuropsychopharmacol Biol Psychiatry. 2011;35(4):959-964.

9. Karila L, Petit A, Cottencin O, et al. Methamphetamine dependence: Consequences and complications. Presse Med. 2010;39(12): 1246-1253. 